\title{
Surface Cover Spectra of the Big Pine Creek Watershed
}

\author{
P.S. Sawyer ${ }^{1}$, H. Stephen ${ }^{2}$ \\ ${ }^{1}$ School of Environmental and Public Affairs, University of Nevada Las Vegas, United States \\ ${ }^{2}$ Department of Civil and Environmental Engineering and Construction, \\ University of Nevada Las Vegas, United States
}

\begin{abstract}
This paper presents a set of spectral reflectance data of numerous surface cover types of the Big Pine Creek watershed in California's Eastern Sierra Nevada Mountains. Ground cover vegetative types include several samples of deciduous broad leaf and narrow leaf trees, needle leaf conifers, sages, and needle leaf and broad leaf shrubs. In addition, several litter samples as well as soil and rock spectra are presented. Samples were collected in July 2014 and analyzed in the laboratory using a 0.35 to $2.5 \square m$ Advanced Spectral Devices $(A S D)$ Flexscan spectroradiometer.
\end{abstract}

Keywords: Landsat, ENVI, vegetation spectra, Alpine watershed

\section{INTRODUCTION}

Alpine ecosystems are crucial laboratories for the study of how changing climatic variables will impact local species assemblages. The steep elevation gradients in these regions provides for analysis of several ecotones within a small area. The biomes that inhabit these areas are particularly susceptible to changing environmental parameters since many exist at the limits of their ranges (Lindner et al., 2010). Since alpine ecotones represent bioclimatic transitions, species compositional change is high and susceptible to slight alteration in bioclimatic regimes (Grabherr et al., 2010). Our ability to identify where changes are taking place in these sensitive regions depends upon our ability to exploit existing data sets such as the Landsat Climate Data Record. Understanding the spectral characteristics of the surface cover constituents is essential to being able to identify changes at the local vegetative assembly scale.

Spectral characteristics measured with remote sensing instruments such as the Landsat 5 Thematic Mapper (TM) and Landsat 7 Enhanced Thematic Mapper $\left(\mathrm{ETM}^{+}\right)$enable us to analyze ecological properties of vegetation. Vegetation has characteristic spectral responses such as low red reflectance due to chlorophyll absorption and high near infrared (NIR) reflectance due to the reflectance of the internal structures of the canopy (Wessman, 1992). Changes in surface reflectance can thus be correlated with variation in vegetative cover and plant health.

Soil also demonstrates unique spectral characteristics depending on properties such as its moisture, organic matter content and texture (Jackson et al., 1986). Lower soil moisture content, a possible indicator of water stress in vegetation, would cause higher surface reflectance in the mid-wave infrared (MWIR) region that can be detected using Landsat data (Musick and Pelletier, 1988). Remote sensing using multispectral imagers such as the Landsat series provide a wealth of data that can be used to monitor for changes in the environment. Large scale regional change are clearly evident from the 30 meter resolution imagery these instruments provide. However, at this resolution, important details within each pixel remain hidden. For remote sensing applications, unless the image is over human controlled agricultural plots, most Landsat image pixels will include several components that cannot be discerned from the raw data. This necessitates the use of spectral unmixing techniques such as spectral mixture analysis (SMA). With SMA, the radiance measured in each pixel by the sensor in each wave band is composed of a mixture of reflectance energies given off by each of the individual components within that pixel. Studies performing subpixel analysis of Landsat imagery often make use of generic spectral libraries of various vegetative species to identify spectral endmembers that make up the constituents of each pixel.

This study is designed to provide a spectral library of the vegetative and other ground cover types present within the Big Pine Creek watershed. Spectral response data of numerous vegetative samples 
in addition to several litter, soil, and rock samples are presented. Sample collection and analysis procedures are explained and the full spectrum reflectance data are provided for each sample. The ground truth spectra developed in this study allow us to decompose the individual spectral components present with each Landsat pixel. From this data, we can then identify the fractional cover of individual species present within each pixel and analyze how those fractions have trended over time. This information can then be used to assess the impact recent climate variations have had on the Big Pine Creek ecosystem.

This research has the added benefit of providing the scientific community with samples of reflectance data commonly encountered in desert and montane environments. Although the samples were obtained from a specific watershed in the Eastern Sierra Nevada Mountains of California, most of the species are ubiquitous throughout the inter-mountain and great basin regions of the western United States.

\section{Study ARea AND SAMPle DeSCRIPTION}

\subsection{Study Area Description}

Figure 1 below shows the Big Pine Creek watershed located in California's Eastern Sierra Mountains. Big Pine Creek is a major tributary to the Owens River which is a significant source of fresh water for Los Angeles. The Owens River valley straddles the Great Basin and Mojave deserts with vegetation consisting primarily of pine forests at higher elevations and xeric species at lower elevations. Areas bordering streams and the Owens River are primarily grass dominated meadows (Elmore et al., 2003). Elevation within the watershed increases from East to West with the higher regions dominated by barren rock and woodlands with the lower regions dominated by mixed desert shrubs.

The Big Pine Creek watershed ecosystem owes its existence to snow melt and melt-water from the Palisade Glacier. In addition to being the southern-most glacier in the United States, it is also the largest glacier in the Sierras with a surface area of $1.3 \mathrm{~km}^{2}$. It was formed about 3,200 years ago, reaching a maximum extent as recently as 170 years ago (Bowerman and Clark, 2011). It has been generally in retreat ever since. The Big Pine Creek watershed drainage area covers approximately 82 $\mathrm{km}^{2}$ and its average flow is $1.8 \mathrm{~m}^{3} / \mathrm{s}$.

\section{Big Pine Creek Watershed on the Eastern Slopes} of California's Eastern Sierra Mountains

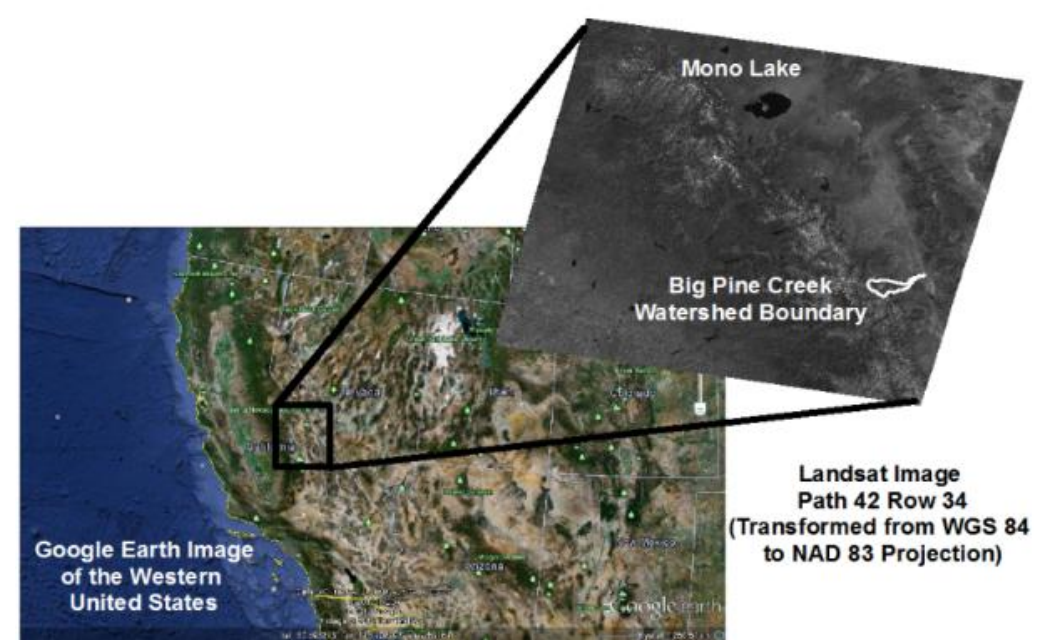

Figure1. Study Area Location Showing the Boundary of the Big Pine Creek Watershed

\subsection{Sample Collection}

The Big Pine Creek watershed consists of mostly undeveloped rugged terrain within the Inyo National Forest. Due to the remoteness and steep gradients, performing the spectral measurements in the field was not practical. Therefore, the vegetative and other surface constituent samples were collected and placed in sealed plastic bags and placed on ice for shipment to the lab. Samples were selected by choosing the top two or three vegetative surface cover types at each site along with a litter or soil sample when practical. Figure 2 shows the locations of each sample site within the watershed. Table 1 provides the geographic coordinates and elevations of each site. 


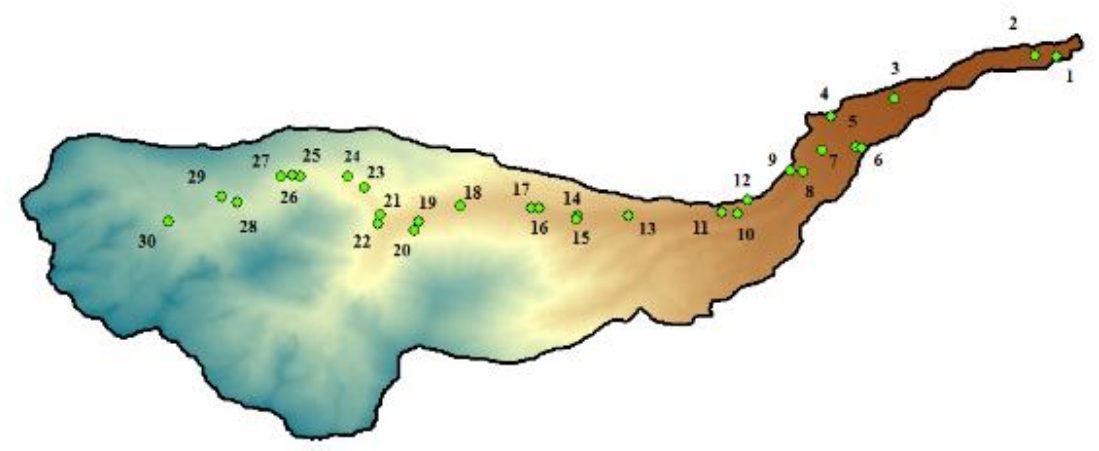

\footnotetext{
Legend

Meters Above

Mean Sea Lewvel (MSL)

High : 4349

Low : 1193
}

Figure2. Sample Site Locations

Table1. Sample Site Location

\begin{tabular}{|c|c|c|c|c|c|c|c|}
\hline $\begin{array}{c}\text { Sample } \\
\text { Site ID }\end{array}$ & $\begin{array}{c}\text { Latitude } \\
(\mathrm{N})\end{array}$ & $\begin{array}{c}\text { Longitude } \\
(\mathrm{W})\end{array}$ & $\begin{array}{c}\text { Elevation } \\
(\mathrm{M} \text { MSL) }\end{array}$ & $\begin{array}{c}\text { Sample } \\
\text { Site ID }\end{array}$ & $\begin{array}{c}\text { Latitude } \\
(\mathrm{N})\end{array}$ & $\begin{array}{c}\text { Longitude } \\
(\mathrm{W})\end{array}$ & $\begin{array}{c}\text { Elevation } \\
(\mathrm{M} \text { MSL) }\end{array}$ \\
\hline 1 & 37.1675 & -118.2657 & 1201 & 16 & 37.1274 & -118.4024 & 2198 \\
\hline 2 & 37.1676 & -118.2714 & 1201 & 17 & 37.1275 & -118.4044 & 2208 \\
\hline 3 & 37.1567 & -118.3070 & 1294 & 18 & 37.1279 & -118.4231 & 2296 \\
\hline 4 & 37.1516 & -118.3251 & 1397 & 19 & 37.1240 & -118.4340 & 2389 \\
\hline 5 & 37.1435 & -118.3187 & 1402 & 20 & 37.1221 & -118.4421 & 2408 \\
\hline 6 & 37.1433 & -118.3172 & 1403 & 21 & 37.1256 & -118.4442 & 2495 \\
\hline 7 & 37.1426 & -118.3274 & 1460 & 22 & 37.1232 & -118.4449 & 2502 \\
\hline 8 & 37.1370 & -118.3326 & 1509 & 23 & 37.1328 & -118.4485 & 2603 \\
\hline 9 & 37.1372 & -118.3359 & 1598 & 24 & 37.1358 & -118.4529 & 2702 \\
\hline 10 & 37.1258 & -118.3499 & 1707 & 25 & 37.1358 & -118.4653 & 2799 \\
\hline 11 & 37.1264 & -118.3541 & 1798 & 26 & 37.1359 & -118.4675 & 2836 \\
\hline 12 & 37.1294 & -118.3471 & 1805 & 27 & 37.1357 & -118.4703 & 2899 \\
\hline 13 & 37.1252 & -118.3788 & 2009 & 28 & 37.1290 & -118.4820 & 3005 \\
\hline 14 & 37.1253 & -118.3922 & 2100 & 29 & 37.1305 & -118.4863 & 3099 \\
\hline 15 & 37.1246 & -118.3923 & 2105 & 30 & 37.1238 & -118.5002 & 3198 \\
\hline
\end{tabular}

\subsection{Sample Analysis}

All of the samples were analyzed within two hours of their arrival at the laboratory. Analysis was performed using an ASD 0.35 - $2.5 \square \mathrm{m}$ VNIR-SWIR Flexscan Spectroradiometer (S/N 16232). Composite spectra of each species as well as combined composite spectra for each type were developed by first averaging the spectra of each species and then averaging the composites. These data are presented in section 3 .

\section{Data Results}

This section presents the results of the sample collection and spectral analysis. The samples collected in this study were for the purpose of performing an analysis of the surface reflectance of the study area and how the reflectance has trended over the last three decades. Endmember spectra were collected from a broad sample of surface cover types at 30 sample sites located throughout the watershed. At each site, three to four samples of the predominant surface covers were collected for analysis. Sample cover types include six categories of photosynthetic vegetation, litter, and barren surface. 


\subsection{Photosynthetic Vegetation}

Photosynthetic vegetation are categorized as trees (three types) or shrubs (three types). The three types of trees include broad leaf, narrow leaf, and needle leaf. The three shrub types include sages, broad leaf shrubs and needle leaf shrubs. Sedges were also analyzed and categorized as needle leaf shrub for this analysis.

\subsubsection{Trees}

\subsubsection{Broad Leaf Trees}

Broad leaf tree samples collected include Black Cottonwood (Populus trichocarpa), Water Birch (Betula occidentalis), Aspen (Populus tremuloides), and Mountain Maple (Acer glaber). Figure 3 shows the composite spectra of each species and a combined composite of all broad leaf tree species. The red data points represent the spectral values at the midpoint of the Landsat 5 TM spectral bands.

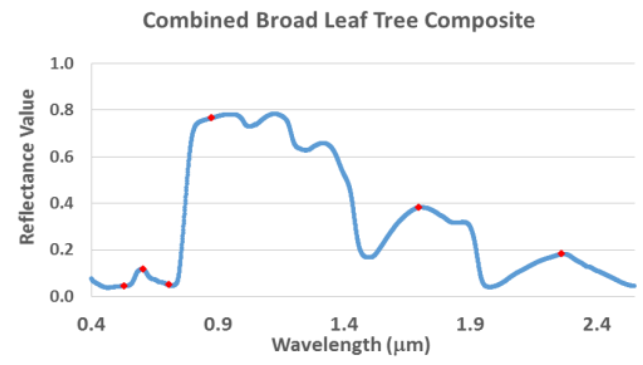

a. Combined full spectrum composite

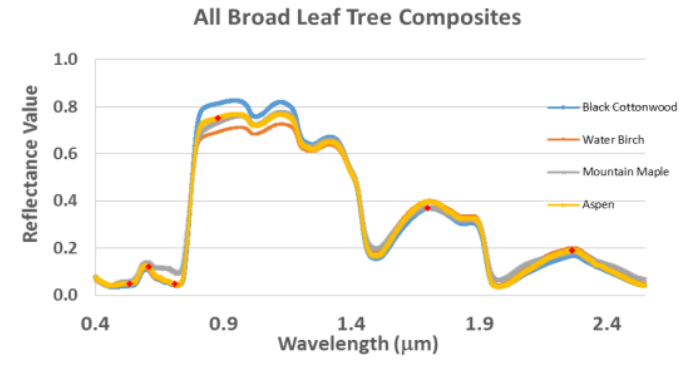

b. Full Spectrum composite of all species

Figure3. Composite Broad Leaf Tree Spectra, Full VNIR-SWIR

\subsubsection{Narrow Leaf Trees}

Narrow leaf tree samples collected include Willow (Salix sp.), Sandbar willow (Salix exigua), and California Coffeeberry (Frangula californica ssp. cuspidata). Figure 4 shows the composite spectra of each species and a combined composite of all narrow leaf tree species. The red data points represent the spectral values at the midpoint of the Landsat 5 TM spectral bands.

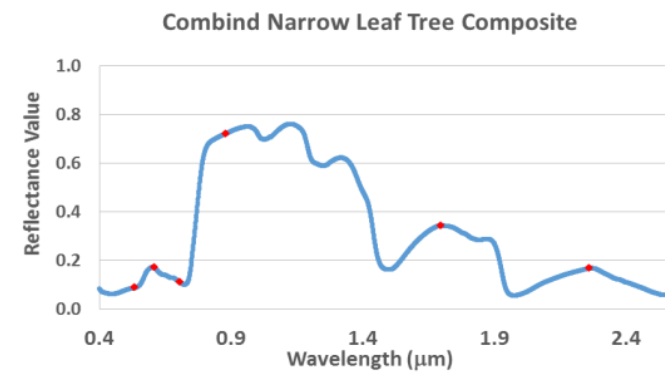

a. Combined full spectrum composite

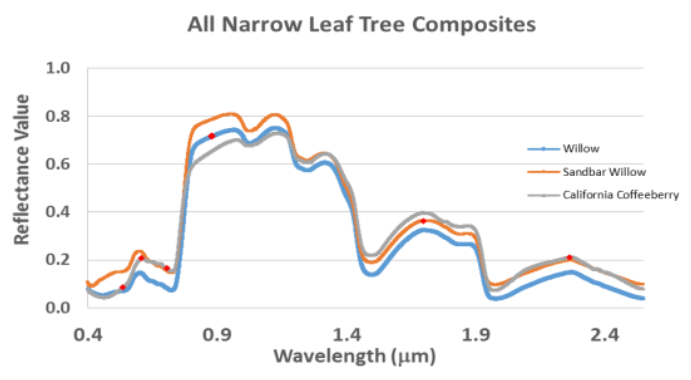

b. Full Spectrum composite of all species

Figure4. Composite Narrow Leaf Tree Spectra, Full VNIR-SWIR

\subsubsection{Needle Leaf Trees}

Needle leaf tree samples collected include Yellow Pine (Pinus sp.), White Pine (Pinus sp.), and California Lodgepole Pine (Pinus contorta var. murrayana). Figure 5 shows the composite spectra of each species and a combined composite of all needle tree species. The red data points represent the spectral values at the midpoint of the Landsat 5 TM spectral bands.
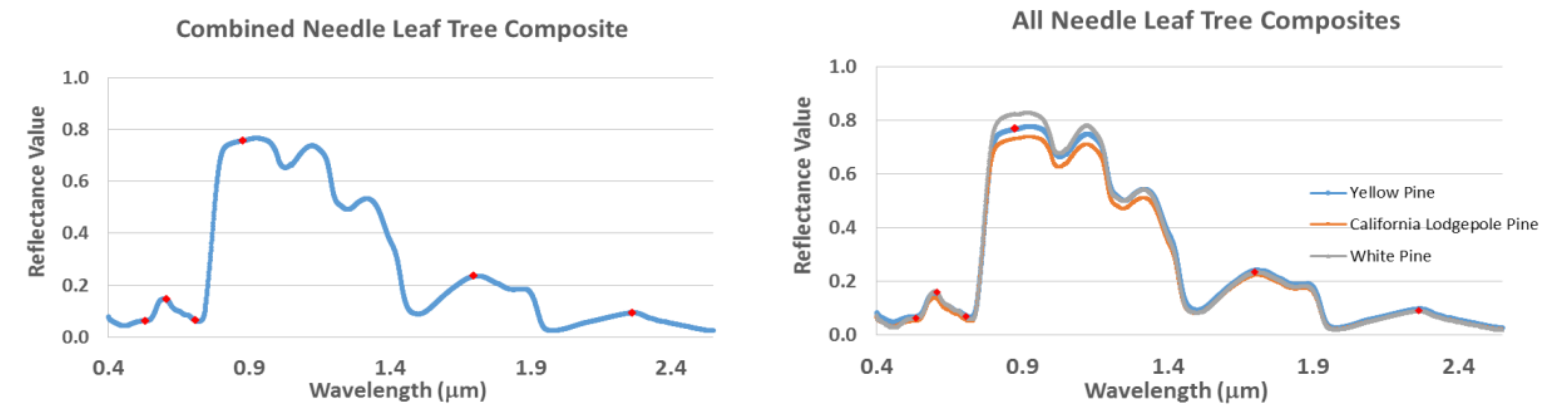

a. Combined full spectrum composite b. Full Spectrum composite of all species

Figure5. Composite needle leaf tree spectra, full VNIR-SWIR 


\subsubsection{Shrubs and Sedges}

Three broad categories of shrubs were sampled including sages, needle leaf shrubs and broad leaf shrubs. Sedges are grouped with the needle lead shrubs.

\subsubsection{Sages}

Four sage types were identified in this study, Sagebrush (Artemisia sp.), Black Sagebrush (Artemisia nova), Big Sagebrush (Artemisia tridentata), and Low Sagebrush (Artemisia arbuscula). Figure 6 shows the composite spectra of each species and a combined composite of all sage shrub species. The red data points represent the spectral values at the midpoint of the Landsat 5 TM spectral bands.

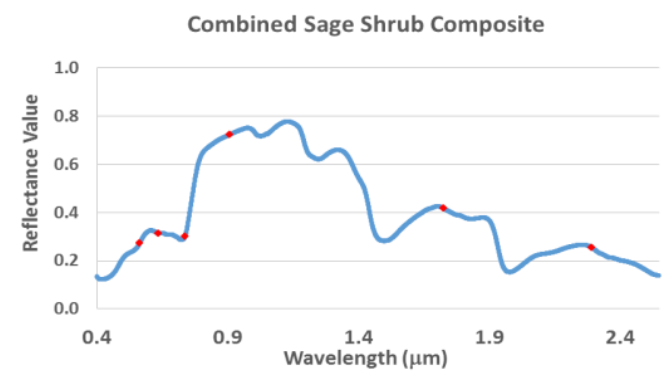

a. Combined Full Spectrum Composite

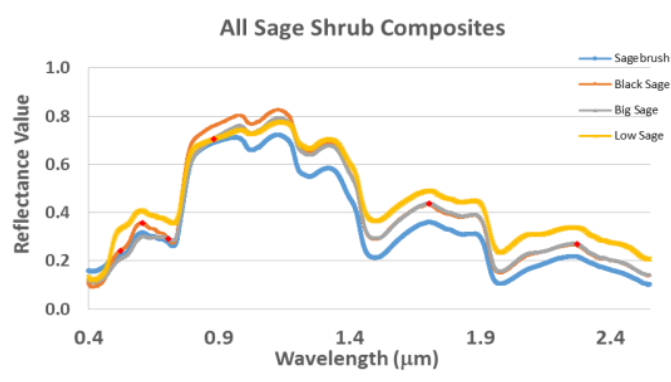

b. Full Spectrum Composite of All Species

Figure6. Composite Sage Shrub Spectra, Full VNIR-SWIR

\subsubsection{Broad Leaf Shrubs}

Five broad leaf shrub species were identified in this study, Curlleaf Mountain-Mahogany (Cercocarpus ledifolius), Desert peach (Prunus andersonii), Greenleaf manzanita (Arctostaphylos patula), Borage (Mertensia oblongifolia), and California Lilac (Ceanothus spinosus). Figure 8 shows the composite spectra of each species and a combined composite of all broad leaf shrub species. The red data points represent the spectral values at the midpoint of the Landsat 5 TM spectral bands.

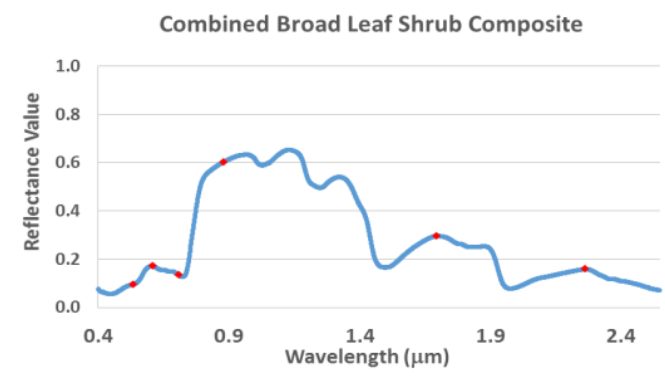

a. Combined full spectrum composite

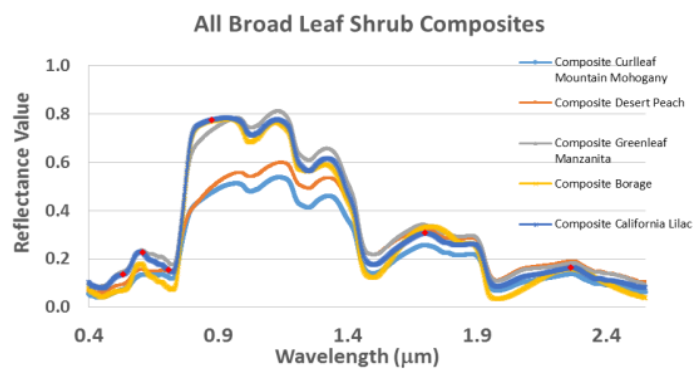

b. Full Spectrum composite of all species

Figure7. Composite Broad Leaf Shrub Spectra, Full VNIR-SWIR

\subsubsection{Needle Leaf Shrubs and Sedges}

Eight needle leaf shrub species were identified in this study including, Rabbitbrish (Chrysothamnus (Ericameria)), Greasewood (Sarcobatus vermiculatus), Tumbleweed (Kali Tragus), Bitterbrush (Purshia tridentata), Green Ephedra (Ephedra viridis), Sulphur Flower (Eriogonum umbellatum), Buckwheat (Eriogonum sp.), and Sedge (Carex sp.). Figure 7 shows the composite spectra of each species and a combined composite of all needle leaf shrub species. The red data points represent the spectral values at the midpoint of the Landsat 5 TM spectral bands.

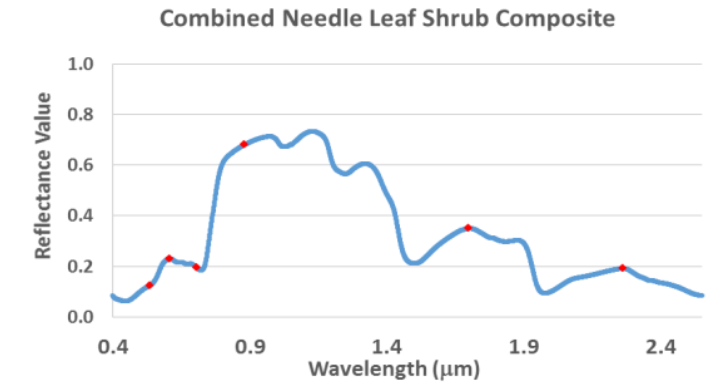

a. Combined Full Spectrum Composite

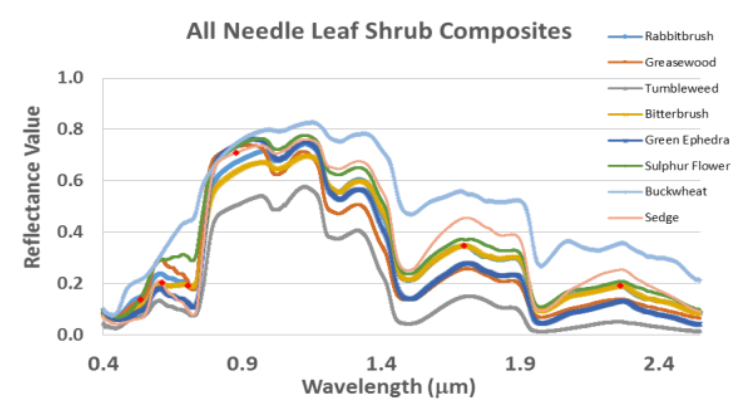

b. Full Spectrum Composite of All Species

Figure8. Composite Needle Leaf Shrub Spectra, Full VNIR-SWIR 


\subsection{Litter}

A total of fourteen litter samples were collected. Figure 9 shows the composite spectra of all litter samples. The red data points represent the spectral values at the midpoint of the Landsat $5 \mathrm{TM}$ spectral bands.

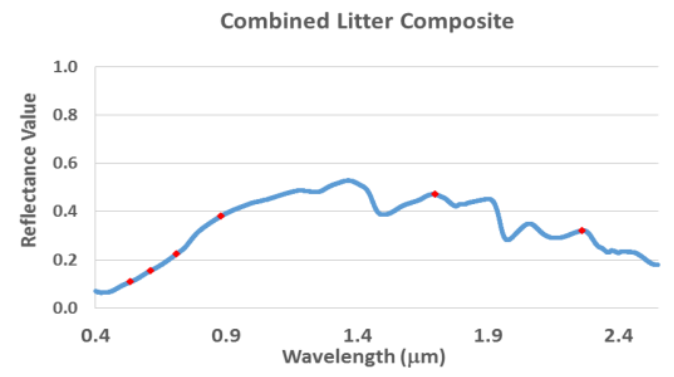

Figure9. Composite Litter Spectra, Full VNIR-SWIR

\subsection{Barren Surface Cover}

Barren surface cover includes seven soil and eight rock samples.

\subsubsection{Soil}

A total of seven soil samples were collected. Figure 10 shows the composite spectra of all soil samples. The red data points represent the spectral values at the midpoint of the Landsat $5 \mathrm{TM}$ spectral bands.

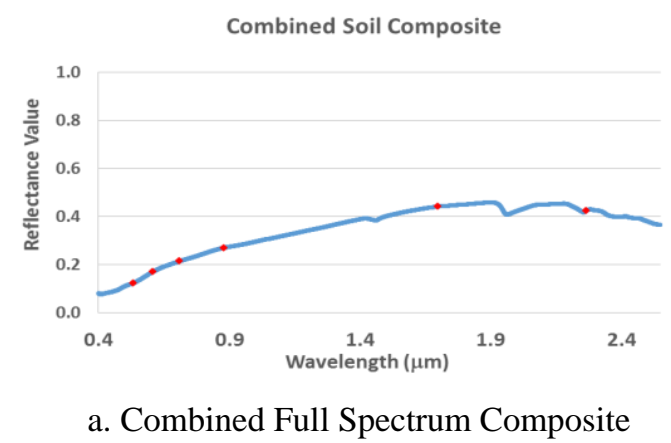

Figure10. Composite Soil Spectra, Full VNIR-SWIR

\subsubsection{Rocks}

A total of eight rock samples were collected. Figure 11 shows the composite spectra of all rock samples. The red data points represent the spectral values at the midpoint of the Landsat $5 \mathrm{TM}$ spectral bands.

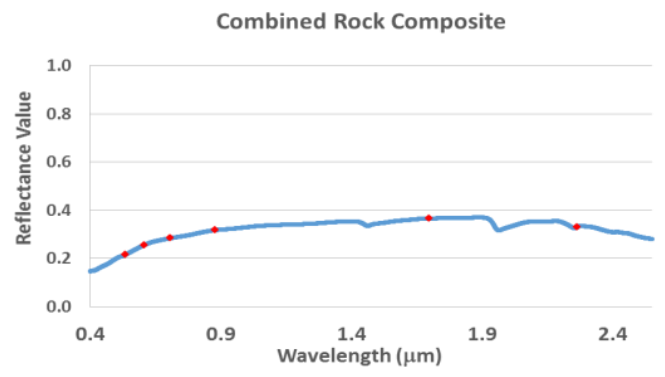

a. Combined full spectrum composite

Figure11. Composite Rock Spectra, Full VNIR-SWIR

\section{RESUlTS AND DisCUSSION}

\subsection{Ground Truth End Member Spectra}

A total of 116 surface cover samples located throughout the study area were collected in situ during July 2014 including three to four samples from each of the 30 sample sites used in this study. The surface cover types are classified as either photosynthetic vegetation (PV), non-photosynthetic vegetation (NPV), or barren surface. There were six broad categories of PV present: broad leaf trees; narrow leaf trees; needle leaf trees; sage bush; broad leaf shrubs; and needle leaf shrubs. 
Figure 12 shows examples of the three tree sample types collected and how the samples looked as they were being analyzed in the lab. The three shrub types are shown in figure 13.

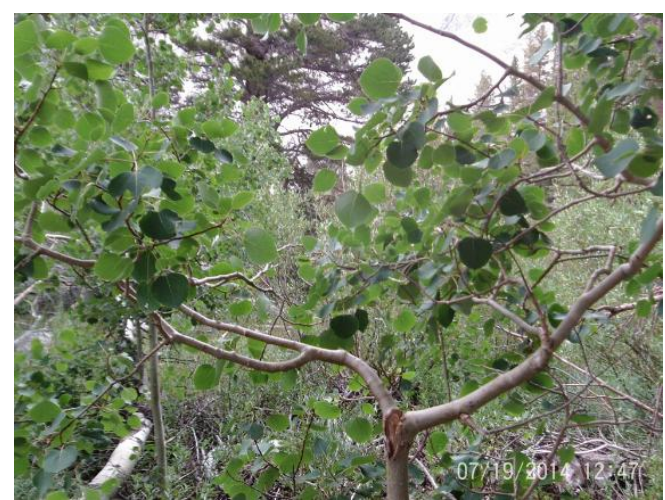

a. Broad leaf (Aspen - Populus tremuloides)

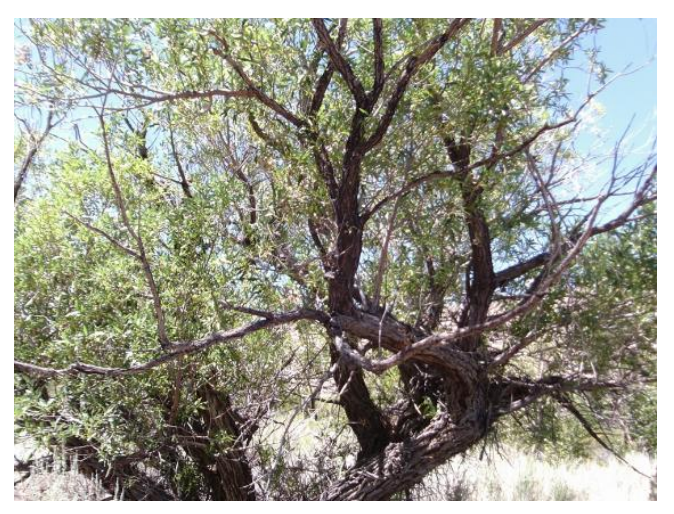

b. Narrow leaf (Willow - Salix sp.)

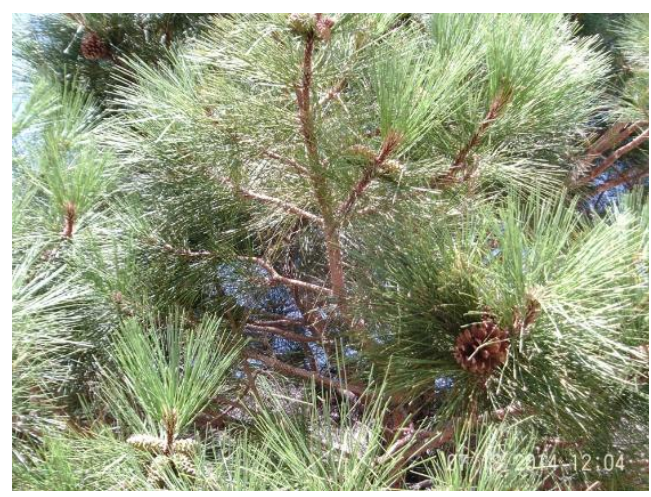

c. Needle leaf (Pine - Pinus sp.)

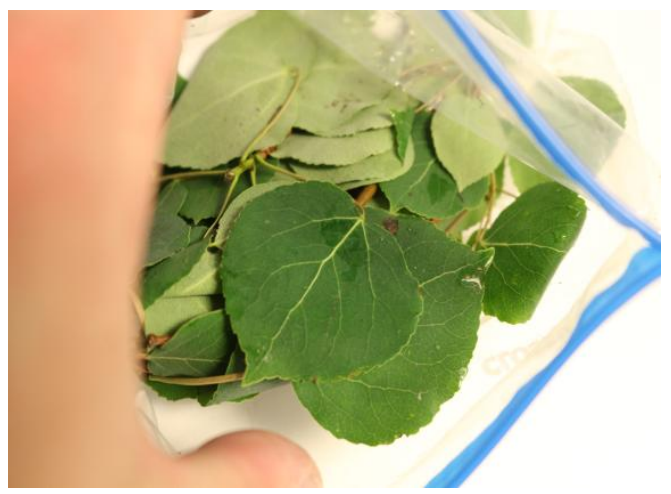

Broad leaf sample as analyzed in the lab

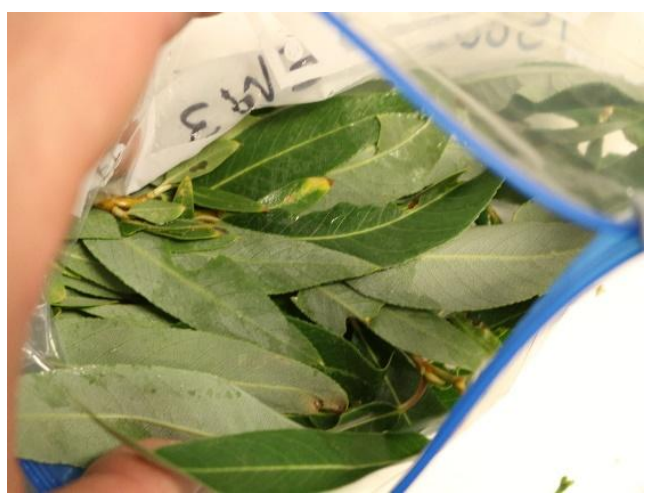

Narrow leaf sample as analyzed in the lab

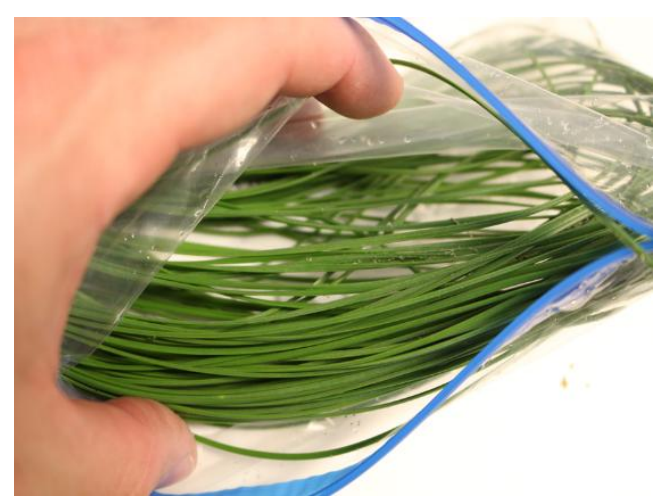

Needle leaf sample as analyzed in the lab

Figure12. Samples of Study Area Trees.A - Populus Tremuloides, B - Salix Sp. And C - Pinus Sp

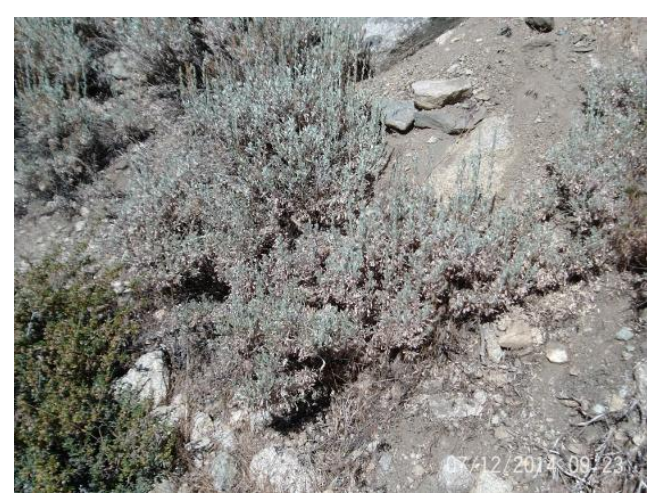

a. Sage (Big sage - Artemisia tridentata)

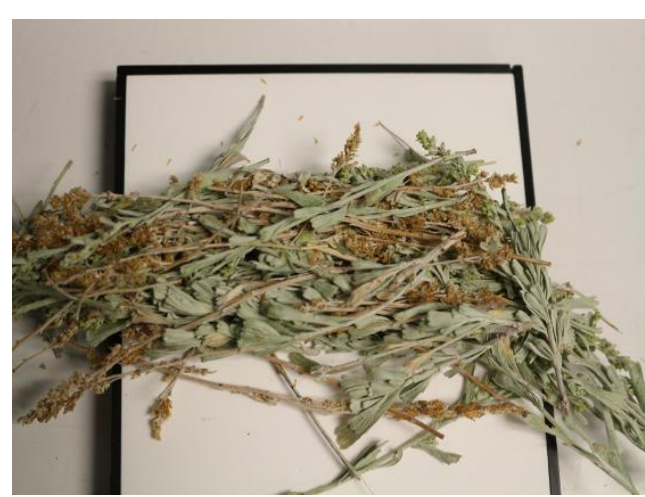

Sage sample as analyzed in the lab 


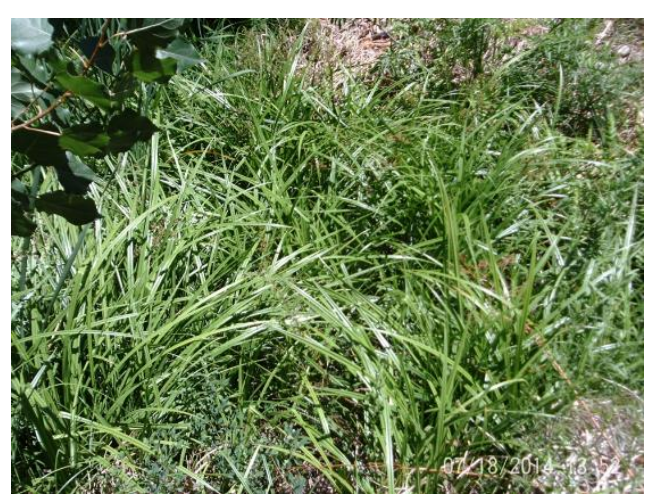

b. Needle leaf sedge (Sedge - Carex sp.)

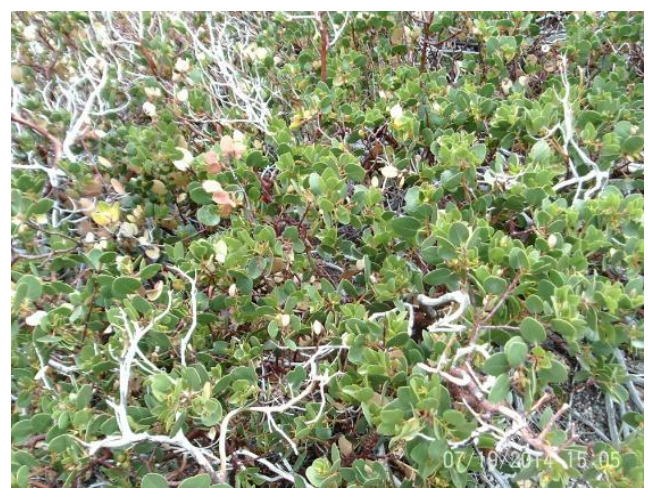

c. Broad leaf shrub (Greenleaf Manzanita Arctostaphylos paula)

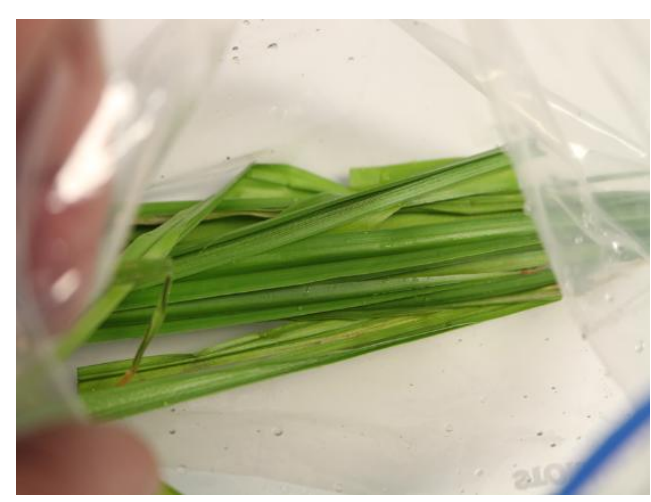

Needle leaf shrub sample as analyzed in the lab

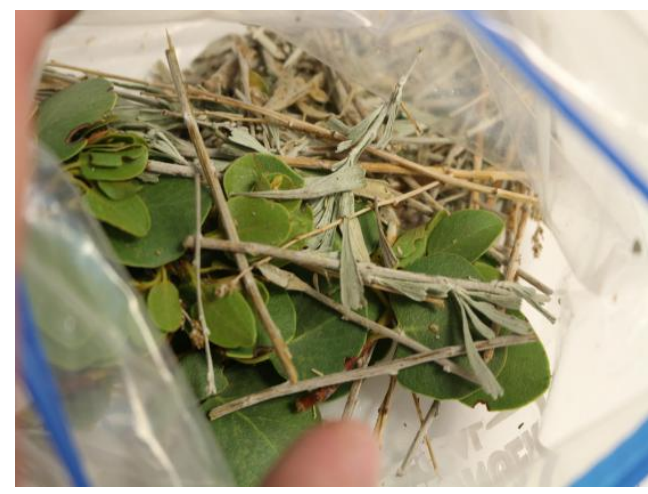

Broad leaf shrub sample as analyzed in the lab

Figure13. Samples of Study Area Sedge and Shrubs; $a$-Artemisia Tridentata, $b$ - Carex Sp. and c Arctostaphylos Paula

Most of the vegetation spectra have the characteristic vegetation spectral curve shape with subtle differences in amplitude and where specific peak reflectance's are present which are unique to individual species. One exception was one of the desert peach samples. This is most likely a result of the sampling methodology in which the spectral analyzer fore optics captured more of the stem than the leaf. This resulted in a flattened spectra. Another outlier was the Buckwheat sample which produced a unique spectra, especially in the visible bands that are distinctly different from all the other shrubs.

\section{Summary AND CONCLUSIONS}

This paper presents VNIR-SWIR $0.35 \mu \mathrm{m}-2.5 \mu \mathrm{m}$ spectra of numerous vegetative, litter and barren surface cover types from the Big Pine Creek watershed. The spectra were analyzed in the lab using an ASD Flexscan Spectroradiometer. Composite spectra for the full VNIR-SWIR for each predominant surface cover type were presented. All of the individual sample spectra are available for download from google drive (Big Pine Creek Surface Cover Spectra.docx). The raw spectral data from each sample are also available for download on google drive (sample site VNIR-SWIR spectra).

The data presented in this paper are intended for public use in the analysis of remote sensed imagery. The spectra can be used to assist analysts in the identification of surface features, especially in remote areas that do not have historical surface cover composition data. Litter and soil samples are provided as these surface cover types will account for a significant percentage of any remote sensed image. Ground truth spectra are important elements of successful spectral unmixing studies of remote areas. These studies can take advantage of the more than three decades of continuous Landsat data covering the globe to identify changes taking place in our environment that pose significant challenges to sustainability. 


\section{REFERENCES}

Bowerman, N.D. and Clark, D.H., Holocene glaciation of the central Sierra Nevada, California. Quaternary Science Reviews. 30, pp. 1067-1085, 2011

Elmore, A.J., Mustard, J.F., and Manning, S.J., Regional patterns of plant community response to changes in water: Owens Valley, California. Ecological Applications, 13 (2), pp. 443-460, 2003.

Grabherr, G., Gottfried, M., and Pauli, H., Climate change impacts in Alpine environments. Geography Compass, 48, pp. 1133-1153, 2010.

Jackson, R.D., Pinter, P.J., Jr., Reginato, R.J., and Idso, S.B., Detection and evaluation of plant stresses for crop management decisions. IEEE Transactions on Geoscience and Remote Sensing, GE-24 (1), pp. 99-106, 1986.

Lindner, M., Maroschek, M., Netherer, S., Kremer, A., Barbati, A., Garcia-Gonzalo, J., Seidl, R., Delzon, S., Corona, P., Kolstrom, M., Lexer, M.J., and Marchetti, M., Climate change impacts, adaptive capacity, and vulnerability of European forest ecosystems. Forest Ecology and Management, 259, pp. 698 - 709, 2010.

Musick, H.B. and Pelletier, R.E., Response to soil moisture spectral indexes derived from bidirectional reflectance in thematic mapper wavebands. Remote Sensing of Environment, 25, pp. 167-184, 1988.

Wessman, C.A., Imaging spectrometry for remote sensing of ecosystem processes. Advances in Space Research, 12 (7), pp. 361-368, 1992. 